\title{
Review: aspirin reduces the incidence of coronary artery disease in people at risk
}

Sanmuganathan PS, Ghahramani P,Jackson PR, Wallis EJ, Ramsay LE. Aspirin for primary prevention of coronary heart disease: safety and absolute benefit related to coronary risk derived from meta-analysis of randomised trials. Heart 2001 Mar;85:265-71.

QUESTION: In people at risk, what is the effectiveness of aspirin for primary prevention of coronary artery disease (CAD)?

\section{Data sources}

Randomised controlled trials from 1985 onward were identified by searching Medline with the terms cardiovascular disease and aspirin. Meta-analyses and review articles were also scrutinised.

\section{Study selection}

Studies were selected if they assessed the effectiveness of aspirin for primary prevention of CAD and assessed outcomes that included incidence of myocardial infarction (MI), stroke, all cardiovascular events (MI, stroke, and cardiovascular deaths), bleeding complications, and all-cause mortality.

\section{Data extraction}

Data were extracted on study sample size, patient characteristics, key components of the intervention, duration of intervention, and outcomes.

\section{Main results}

4 trials (48 540 patients) were included in the metaanalysis. 25133 patients received aspirin, and 23407 received placebo. The incidence of MI and all cardiovascular events was higher in the placebo group than in the aspirin group (table). The groups did not differ for the incidence of stroke or all-cause mortality (table). The incidence of bleeding complications was higher in the aspirin group than in the placebo group (table). For patients with risk of CAD $\geqslant 1.5 \%$ per year, treatment with aspirin for primary prevention was reported to be valuable and safe with benefits likely to outweigh harms (figure).

\section{Conclusions}

In people at risk, aspirin reduces the incidence of coronary artery disease. This reduction is associated with an increase in the incidence of bleeding complications.
Source of funding: not stated.

For correspondence: Professor L E Ramsay, Clinical Pharmacology and Therapeutics, Royal Hallamshire Hospital, Glossop Road, Sheffield

S10 2JF, UK. Fax +44 (0) 1142721275 .

Aspirin v placebo for primary prevention of coronary artery disease ${ }^{*}$

\begin{tabular}{|c|c|c|c|c|}
\hline \multirow{2}{*}{$\begin{array}{l}\text { Outcomes at } 3.8 \\
\text { to } 6.8 \text { years }\end{array}$} & \multicolumn{2}{|c|}{$\begin{array}{l}\text { Weighted event } \\
\text { rates }\end{array}$} & \multirow[b]{2}{*}{ RRR (95\% CI) } & \multirow[b]{2}{*}{ NNT (Cl) } \\
\hline & Aspirin & Placebo & & \\
\hline Myocardial infarction & $1.7 \%$ & $2.4 \%$ & $30 \%(20$ to 38$)$ & 150 (113 to 224$)$ \\
\hline All cardiovascular events & $4.5 \%$ & $5.2 \%$ & $13 \%(6$ to 19$)$ & 149 (97 to 317$)$ \\
\hline \multirow[t]{2}{*}{ All-cause mortality } & $3.2 \%$ & $3.4 \%$ & $6 \%(-3$ to 14$)$ & Not significant \\
\hline & & & RRI (Cl) & NNH (CI) \\
\hline Stroke & $1.5 \%$ & $1.4 \%$ & $5 \%(-22$ to 9$)$ & Not significant \\
\hline Bleeding complications & $1.0 \%$ & $0.7 \%$ & $63 \%(34$ to 99$)$ & 375 (251 to 739$)$ \\
\hline
\end{tabular}

*Abbreviations defined in glossary; RRR, RRI, NNT, NNH, and Cl calculated from data in original articles.

\section{COMMENTARY}

It is more difficult to assess treatment benefits with primary prevention than with secondary prevention because event rates are lower. This difficulty is shown again in the review by Sanmuganathan et al of aspirin treatment for primary prevention of CAD events. The absolute benefit was a $0.15 \%$ reduction per year in MI compared with an increased risk of $0.04 \%$ per year for major non-cerebral haemorrhage (non-cerebral bleeds causing death, transfusion, or operation) and $0.18 \%$ per year for non-minor haemorrhage (non-cerebral bleeds not classified as minor). Differences in stroke or allcause mortality were not statistically significant.

The 4 trials summarised in this paper have previously been reviewed in the sixth American College of Chest Physicians consensus conference on antithrombotic treatment. ${ }^{1}$ These authors recommended the use of $75 \mathrm{or} 81 \mathrm{mg}$ of aspirin daily for primary prevention because of lower stroke rates in the 2 trials that used this dose compared with the $325 \mathrm{mg}$ daily or every-other-day doses used in the other 2 trials. They also emphasised lowering the diastolic blood pressure below $85 \mathrm{~mm} \mathrm{Hg}$ in patients receiving aspirin for primary prevention. Because the bleeding risk remains constant, whereas the therapeutic benefit and the risk for cardiovascular events increase, treating higher-risk patients makes more clinical sense than does treating everyone. For risk assessment, the consensus conference authors emphasise older age and cardiac risk factors, whereas Sanmuganathan et al offer a modified Sheffield table.

Eric R Bates, MD University of Michigan Ann Arbor, Michigan, USA events) (line A) and absolute harm (increase in major bleeds) (line B) from aspirin treatment, related to absolute cardiovascular event risk. The dotted lines show the $78 \%$ confidence regions. By extrapolation, benefit and harm from aspirin are equal when cardiovascular event risk is $0.22 \%$ year, with an upper $95 \%$ confidence limit for this estimate at a cardiovascular event risk of approximately $0.8 \% /$ year. 